\title{
ADDRESSED BLAME AND HOSTILITY
}

\author{
Benjamin De Mesel
}

0

ENJAMIN BAGLEY sets out a dilemma for addressed blame, that is, blame addressed to its targets as an implicit demand for recognition. ${ }^{1}$ The dilemma arises when we ask whether offenders would actually appreciate this demand, via a sound deliberative route from their existing motivations. "If they would, their offense reflects a deliberative mistake, and blame's hostility seems unnecessary. If they would not, addressing them is futile, and blame's emotional engagement seems unwarranted." ${ }^{2}$

Bagley wants to resolve the dilemma in such a way that addressed blame's distinctive elements of hostility and emotional engagement can be accounted for. ${ }^{3}$ He draws on two ideas from Bernard Williams. First, what someone would conclude via sound deliberation can be indeterminate. Second, addressed blame works proleptically:

In general, blame is proleptic when the ability of its targets to recognize and respond to our demands may depend on our blame itself, and when the nature of our blame reflects this fact.... When we proleptically address blame to offenders, we presuppose that they have a sound deliberative route to the recognition we demand, but we do not presuppose that this is the only such route open to them. The former gives us reason to actively care about their recognition; the latter gives us reason to be hostile. ${ }^{4}$

I accept that hostility and emotional engagement are distinctive elements of addressed blame, and I believe that Bagley's focus on addressed blame's proleptic mechanism helps to resolve his puzzle. I will argue, however, that Bagley has difficulties accounting for the element of hostility in addressed blame, which means that his solution to the dilemma cannot work (section 2). I will suggest that an alternative account of addressed blame avoids these difficulties (section

1 Bagley, "Properly Proleptic Blame."

2 Bagley, "Properly Proleptic Blame," 852.

3 Bagley, "Properly Proleptic Blame," 853.

4 Bagley, "Properly Proleptic Blame," 854. 
3), and reply to an objection (section 4). I will start by introducing Bagley's paradigm example of addressed blame (section 1 ).

\section{ADDRESSED AND NON-ADDRESSED BLAME}

Bagley illustrates the difference between addressed and non-addressed blame by way of a passage from E.M. Forster's novel Howards End in which Margaret Schlegel blames her husband Henry Wilcox.

"Not any more of this!" she cried. "You shall see the connection if it kills you, Henry! You have had a mistress-I forgave you. My sister has a lover-you drive her from the house. Do you see the connection? Stupid, hypocritical, cruel—oh, contemptible! —a man who insults his wife when she's alive and cants with her memory when she's dead.... Only say to yourself: 'What Helen has done, I've done."'

"The two cases are different," Henry stammered....

"In what way different? You have betrayed Mrs. Wilcox, Henry, Helen only herself... You have the insolence to talk to me of differences, Henry?"

Oh, the uselessness of it! Henry's retort came.

"I perceive you are attempting blackmail.... My rule through life has been never to pay the least attention to threats, and I can only repeat what I said before: I do not give you and your sister leave to sleep at Howards End."

Margaret loosed his hands.... For a little she stood looking at the Six Hills, tombs of warriors, breasts of the spring. Then she passed out into what was now the evening. ${ }^{5}$

Margaret's blame at the beginning is very different from her blame at the end. The latter is cold rejection and a paradigm example of non-addressed blame. The former is a paradigm example of addressed blame. Addressed blame is proleptic. When Margaret addresses her blame to Henry, it is not determinate whether his conduct embodies relationship-impairing values. Her blame enables him to specify his values, and the way in which he does so will reveal whether their relationship has a future. Non-addressed blame is not proleptic: Henry has revealed relationship-impairing values, no opportunity to respond is provided, and the case is closed. 


\section{ADDRESSED BLAME AND HOSTILITY}

Bagley intends to show how addressed blame's elements of emotional engagement and hostility can be justified. According to Bagley, what gives us reason to be hostile in addressing blame is that we do not presuppose that the route to recognition of our demands is the only sound deliberative route open to the offender. ${ }^{6}$ Consider also the following passage:

Because [the offender's] conduct also doesn't determinately not embody their values, it can't be written off as a deliberative mistake. This is what explains addressed blame's element of hostility. While you do not have reason to revise your attitudes toward the offender in the ways a defect in their values would warrant, you also do not have reason to respond favorably toward them in the ways you would if their underlying values were in good shape. ${ }^{7}$

The idea seems to be that we have reason to be hostile whenever we do not have reason to respond favorably. We would have reason to respond favorably if the offender's values were in good shape, if the route to recognition were the only sound route open to them. But we do not presuppose this in addressing blame: we leave open the possibility that they have another route, that their values are not in good shape, and as long as that possibility is left open we have no reason to respond favorably. But do we really have reason to be hostile whenever we do not have reason to respond favorably? That does not seem enough: we need a reason not to respond favorably. And even that is not enough: if we accept that some responses are neither hostile nor favorable, we need a positive reason to respond with hostility.

Bagley claims that addressed blame is hostile because "we are ready to op-

6 Bagley, "Properly Proleptic Blame," 854. One might object that only facts about an offender, and not merely what we presuppose or believe about them, can give us reason to be hostile or can justify hostility. It is important to point out here that Bagley's use of "justification" and "reason" is inspired by Williams, "Internal and External Reasons." For a summary of Williams's perspectivist view, see Alvarez, "Reasons for Action." Objectivists about reasons and justification presuppose that whether an agent has a reason to act and whether her action is justified depend solely on the facts. According to perspectivists, by contrast, the "reasons an agent has [and the justification of his action] depend in an important sense on his epistemic perspective, and so an agent can have a normative reason that is a false belief" (Alvarez, "Reasons for Action," sec. 2). As Bagley notes, those who object to the use of "reason" and "justification" in a perspectivist sense "are free to substitute another phrase" (Bagley, "Properly Proleptic Blame," 859). I will use "reason" and "justification" in the way Bagley uses them.

7 Bagley, "Properly Proleptic Blame," 874. 
pose these people should they ultimately refuse to [accept our considerations]." But to be "ready to oppose if ..." is not to be hostile. I am ready to oppose you should you hurt my daughter, and I leave open the possibility that you will, but that does not make hostility toward you justified. To be hostile, my dictionary explains, is to be "opposed." To be "ready to oppose if ..." is not yet to be opposed. Bagley writes that addressed blame's element of hostility "expresses a willingness, should the invitation [to accept our demand] be rejected, to reject the offender in turn." Again, to be hostile is not just to be "willing to reject if..."; it is to reject.

In general, Bagley seems to think that we have reason to be hostile whenever we take it to be possible that offenders will refuse to accept our considerations, that they do not have a sound deliberative route to recognition, or that their values are relationship impairing. He writes that Margaret "treats the relation between Henry's conduct and his values as an open question." ${ }^{10}$ Because she takes it to be possible that his values are relationship impairing, she has no reason to respond favorably. But if there is an open question, she also takes it to be possible that his values are not relationship impairing, so why would she have reason to respond with hostility?

\section{ADDRESSED BLAME: AN ALTERNATIVE SUGGESTION}

I will suggest that, in addressing blame, we respond to what we take to be a fact, rather than a mere possibility, about the offender's values, and that this way of understanding addressed blame helps us to understand why it is hostile.

It does not seem right to describe Margaret as treating the relation between Henry's conduct and his values as an open question. If she would, would she then cry "Not any of more of this!", "Stupid, hypocritical, cruel—oh, contemptible! - a man who insults his wife when she's alive and cants with her memory when she's dead"? Margaret does not express the readiness to oppose Henryshe opposes him. She is not asking an open question about the relation between Henry's conduct and his values. Rather, her addressed blame involves an implicit claim about that relation, something like "Your conduct embodies relationship-impairing values." The difference between her addressed and non-addressed blame lies indeed, as Bagley points out, in the fact that the latter is final in a way that the former is not. But rather than seeing the relation between them as the relation between an explicitly final claim ("No further response allowed!") and an open question, I propose seeing it as the relation between an explicitly final

8 Bagley, "Properly Proleptic Blame," 854.

9 Bagley, "Properly Proleptic Blame," 876.

10 Bagley, "Properly Proleptic Blame," 874. 
claim and a claim that allows for a response (which is not the same as a question or a claim that asks for or invites a response). Margaret claims that Henry's conduct embodied relationship-impairing values; the burden is on Henry to show that it did not. Margaret specifies his values in a certain way ("Only say to yourself: 'What Helen has done, I've done."). He gets the opportunity to protest against her way of doing it. He is accused but has the opportunity to appeal. ${ }^{11}$

This way of understanding Margaret's addressed blame makes it possible to see where her hostility comes from. She believes (that is, takes it to be a fact) that Henry's values are relationship impairing, that he does not have a sound deliberative route to recognition, and this belief justifies her hostility or, at least, comes closer to justifying it than the belief that it is possible that his values are relationship impairing. One could object that the values of psychopaths are relationship impairing, and that they do not have a sound deliberative route to recognition, while many think that hostile blame toward them would be unjustified. Those who think that hostile blame toward psychopaths is unjustified, however, tend to think that blaming them is in general unjustified: to the extent that psychopaths are not responsible agents, they are not blameworthy, which is why hostile blame cannot be justified. By contrast, Henry is treated by Margaret as a responsible agent, as someone who is at least partly responsible for the fact that his values are relationship impairing. She does not see him as someone who cannot connect, but as someone who has "refused to connect." 12 His refusal gives her reason to be hostile; were he unable to connect, the case would be different.

It could be asked why Margaret, if she really believes that Henry's conduct embodies relationship-impairing values, addresses blame to him instead of finally rejecting him? Why does he get the opportunity to respond? I believe that it would be an overintellectualization to think that one stops caring as soon as one believes that an offender's conduct embodies relationship-impairing values. Because Margaret cares, she wants to be certain of what she believes before ending the relationship. As long as she is not certain, that is, has not ruled out the possibility that Henry's conduct does not embody relationship-impairing values, her

Both my view and Bagley's can be understood as specifications of McKenna's account. McKenna writes that, when we address blame, the blamed agent "is afforded the opportunity to offer some explanation" ("Directed Blame and Conversation," 133 ). This can be specified in at least two ways. According to Bagley, we invite them to offer some explanation; we ask for it. According to my view, we make a claim that allows for a response. In both cases, we make a move in a conversation (a question or invitation versus a claim), and in both cases the blamed agent is afforded the opportunity to make a further move by offering some explanation.

12 Forster, Howards End, 350, emphasis added. 
emotional engagement is fitting (I agree with Bagley here). ${ }^{13}$ This implies that, in my view (as opposed to Bagley's), there is an asymmetry between the justification of emotional engagement and the justification of hostility: while hostility cannot be justified by the belief that it is possible that another will oppose me, emotional engagement can be justified by the belief that it is possible that another will recognize my demands. I cannot say more about this consequence of my view here, but it seems intuitively right.

If hostility is justified by what we take to be a fact about the offender's values, am I then not justifying hostile non-addressed blame as well? Bagley suggests that non-addressed blame is not hostile, but how could that be the case if it involves the certainty that an offender's values are relationship impairing? ${ }^{14} \mathrm{I}$ cannot do justice to the complexity of non-addressed blame here, but my point about emotional engagement helps to sketch a tentative answer. As long as we merely believe that an offender's values are relationship impairing, we do not rule out the possibility that they are not, and emotional engagement is fitting. When we are certain that an offender's values are relationship impairing, the possibility that they are not has been ruled out, and emotional engagement is no longer justified. But if emotional engagement is not justified, then neither is hostility, because hostility requires, or is even a kind of, emotional engagement.

My alternative account of addressed blame preserves a crucial difference between addressed and non-addressed blame, thus incorporating Bagley's main insight: addressed blame is proleptic (Henry has the opportunity to respond) in a sense in which non-addressed blame is not, and the proleptic character of addressed blame helps to avoid his dilemma. According to Bagley, that addressed blame is proleptic implies that there is "an essential connection between addressed blame and indeterminacy." 15 I agree, if "indeterminate" means that we do not rule out the possibility that, in response to our blame, the offender might convincingly specify their values in a way that conflicts with our way of specifying them. I disagree if "indeterminate" means that, in addressing blame, we raise a question or manifest uncertainty about the offender's values. ${ }^{16}$

13 On the relation between belief and certainty, as I see it here, see Hacker, The Intellectual Powers, 170-74, 208-9. "Someone who is certain ... has ruled out the possibility of things not being so" (172). "To say that one believes that things are so is, among other things, to imply that not all doubt can rationally be excluded, even though one has no doubts" (208-9). Bagley, "Properly Proleptic Blame," 856. Bagley, "Properly Proleptic Blame," 854. See Bagley's formulations "raising certain questions" and "the sense of uncertainty and tension that [addressed] blame distinctively registers" ("Properly Proleptic Blame," 875, 882). 


\section{AN OBJECTION}

Bagley writes in a footnote that "conduct warranting addressed blame certainly reveals relationship-impairing attitudes, just not relationship-impairing values."17 In light of this remark, it is possible to understand Margaret, in addressing her blame, as saying "Your conduct has revealed relationship-impairing attitudes, but it is not clear whether it has revealed relationship-impairing values." This reading seems to leave Bagley's account of addressed blame intact, and one may think it helpful in order to correct Bagley's claim that the justification of addressed blame's hostility is to be found in a possibility about Henry's values: maybe what justifies Margaret's hostility is not her belief in a possibility about Henry's values, but her belief that his conduct has actually revealed relationship-impairing attitudes.

There is a difficulty about the difference between relationship-impairing attitudes and relationship-impairing values. According to Bagley, Margaret's conclusion that Henry's conduct embodies relationship-impairing values is the conclusion that she can no longer have a loving relationship with him. It justifies final rejection. Similarly, relationship-impairing attitudes might be understood as attitudes that make a relationship impossible. If they do, it becomes unclear why, in Bagley's view, relationship-impairing attitudes do not justify final rejection, while relationship-impairing values do. So he must mean something different by "relationship-impairing attitudes." Here is another possibility. Suppose that a friend promises to water my plant while I am away but then forgets about it. According to Bagley, this is conduct warranting addressed blame, and so it can be said to reveal relationship-impairing attitudes. ${ }^{18}$ But if this is what relationship-impairing attitudes are, they do not justify hostility. Suppose that my friend has a perfectly good explanation for why she forgot to water the plant. Then our relationship may not be impaired at all, to use the term "relationship impairing" for the attitude revealed in her conduct is misleading, and hostility was never justified. The bare fact that someone has done something cannot justify hostility as long as we are unclear about its meaning, about whether it expresses ill will or not.

The most plausible interpretation of "relationship-impairing attitudes" lies somewhere in between the two interpretations mentioned above: to reveal relationship-impairing attitudes is to reveal poor quality of will. It is not yet to reveal relationship-impairing values, because the latter require the poor quality of will to be rooted in underlying evaluative commitments. Suppose that we un- 
derstand the relation between relationship-impairing attitudes and values in this way. Would it then be helpful to understand Margaret, in addressing her blame, as saying "Your conduct has revealed relationship-impairing attitudes, but it is not clear whether it has revealed relationship-impairing values," where the first part accounts for her hostility? I see some problems with this reading. First, Margaret is not saying that she is unclear about something. It could be argued, in response to this, that the "but it is not clear" part should be left out of Margaret's addressed blame. The suggestion would then be that her addressed blame expresses something like "Your conduct has revealed relationship-impairing attitudes," while her non-addressed blame is rather like "Your conduct has revealed relationship-impairing values.” But this suggestion cannot be Bagley's: there is no open question, no invitation, no uncertainty. Moreover, it does not capture what Margaret communicates to Henry. She does not just sum up disconnected cases where Henry has shown disregard; she suggests that these cases exhibit a pattern ("a man who insults his wife ... cants with her memory ... ruins a woman for pleasure ... casts her off to ruin other men ... gives bad financial advice"), and that is why her addressed blame is closer to "Your conduct has revealed relationship-impairing values."

\section{CONCLUSION}

I conclude that Bagley's account of addressed blame makes it difficult to understand why addressed blame is hostile. My alternative suggestion (1) makes better sense of Bagley's paradigm example of addressed blame, (2) avoids Bagley's dilemma in the way Bagley's original solution does, because it preserves addressed blame's proleptic character, and (3) can account for addressed blame's elements of emotional engagement and hostility. ${ }^{19}$

KU Leuven

benjamin.demesel@kuleuven.be

REFERENCES

Alvarez, Maria. "Reasons for Action: Justification, Motivation, Explanation."

19 This work was funded by the Research Foundation Flanders (Fwo). I would like to thank Samuel Reis-Dennis and two anonymous reviewers for very helpful comments and suggestions. 
Stanford Encyclopedia of Philosophy (Winter 2017). https://plato.stanford. edu/entries/reasons-just-vs-expl/.

Bagley, Benjamin. "Properly Proleptic Blame." Ethics 127, no. 4 (July 2017): 85282.

Forster, E. M. Howards End. 1910. London: Penguin, 2012.

Hacker, P.M. S. The Intellectual Powers: A Study of Human Nature. Oxford: Wiley-Blackwell, 2013.

McKenna, Michael. "Directed Blame and Conversation." In Blame: Its Nature and Norms, edited by D. Justin Coates and Neal A. Tognazzini, 119-40. Oxford: Oxford University Press, 2013.

Williams, Bernard. "Internal and External Reasons." In Moral Luck, 101-13. Cambridge: Cambridge University Press, 1981. 